\title{
ASSESSING THE INTENSITY OF URBAN HEAT ISLAND EFFECT IN THE HOT HUMID CITY OF CHENNAI
}

\author{
Lilly Rose A. , Monsingh D.Devadas ${ }^{2}$ \\ ${ }^{1}$ Research Scholar, School of Architecture and Planning, Anna University, Chennai, India \\ ${ }^{2}$ School of Architecture and Planning, Anna University, Chennai, India \\ E-mail : 'lillyini@gmail.com
}

\begin{abstract}
Creation of cities leads to the removal of natural landscape with built up spaces, parking lots, roads etc, through highly reflective materials, affecting the local climate in a dramatic scale. The climatic changes in the urban areas are often characterized by increase in air temperatures and are termed as the Urban Heat Island Effect (UHIE). Major factors contributing to the elevated air temperatures include the size of the city, population, density of built-up spaces, street canyon geometry, thermal properties of materials, degree of vegetation and waste heat from buildings. Therefore it is vital for urban designers and urban planners to study the nature of the climate variation trends in urban areas to equip them in planning sustainable and comfortable cities, and mitigate the adverse effects. This paper aims to assess the intensity of urban heat island effect in the city of Chennai and their relationship to various urban factors, through stationary and mobile recordings of urban air temperatures during the hottest month. Air temperatures were recorded in 30 stationary locations covering urban, suburban and rural stations. A mobile survey was also conducted covering the major areas of the city. The results indicate the existence of heat island effect in the city of Chennai with increasing air temperatures in a radial fashion from the suburbs towards the city centre where the mean max UHI intensity reaches $5.5^{\circ} \mathrm{C}$ in stationary survey and $2.53^{\circ} \mathrm{C}$ in the mobile survey. The study reinforces the relationship between the urban air temperature increase and the land-use characteristics. Areas with dense vegetation recorded lesser air temperatures and high density built up spaces along with heavy traffic areas recorded higher temperatures. Further studies between these urban factors and urban air temperatures can lead to arrive at appropriate strategies to mitigate the heat island effect.
\end{abstract}

Key words: Urban Heat Island, Built-up density, Urban air temperatures, Urbanization, Land use, mobile survey.

\section{INTRODUCTION}

Urbanization tremendously changes the landscape of an urban area and results in distinguished climatic conditions termed the "Urban climate". "Urban Climate" is the "Urban effects on local climate" (the changes caused by designers and planners) and the "Urban effects on regional climate" (the differences between what is observed in the city's environs and what would have been observed there if the city was not present on the landscape) (William P. Lowry, 1988). Urban climates are distinguished from those of less built-up areas by differences of air temperature, humidity, wind speed and direction, and amount of precipitation. These differences are mainly due to the alteration of the natural terrain through construction of artificial structures and surfaces. Urban climatology aims to discover, quantify, analyze and construct functional predictive models of the modifications by towns on conditions in the boundary layer (Chandler.T.J, 1976). The understanding of alterations to urban climate is enhanced by Oke's (1976) conception of urban atmosphere into two distinct layers: Urban boundary layer and urban canopy layer. The Urban boundary layer $(\mathrm{UBL})$ is the overall atmospheric system that extends for many miles above the cities. The characteristics of the UBL are partially determined by the city below (Oke 1982). The Urban canyon layer (UCL) is the layer of atmosphere where most life occurs: from ground up to the mean height of roofs. Thus the climatic effects of urbanization are strongly felt in the UCL. According to Lutz Katzschner, (2002) an "ideal urban climate" is an atmospheric situation within the UCL with a high variation in time and space to develop heterogeneous thermal conditions for man within a distance of $150 \mathrm{~m}$. Thus alterations owing to urbanization lead to higher temperatures in urban areas when compared to the surrounding rural area. This difference between urban and rural temperatures is called the "urban-heat-island" (UHI) effect. The main cause of this phenomenon is the faster rate of cooling of the open areas around cities compared with the rate of nocturnal cooling of densely built-up centres (Baruch Givoni, 1998). The causes of the UHI includes, blocking the view to the night sky by buildings, the thermal properties of surface materials and lack of evapotranspiration in urban areas, geometric effects called the "canyon effect and anthropogenic heat (Oke 1982, Santamouris 2002). Diminishing diurnal temperatures (variation between maximum and minimum temperatures) in cities are clear indication of the presence of UHI (Landsberg 1981, Oke 1987). The nighttime effects of UHIs are harmful as it deprives urban residents of the cool relief found in rural areas during the night (Clarke, 1972). 


\section{BACKGROUND ON URBAN HEAT ISLAND}

The awareness of city-induced environment existed for many centuries. The ancient Indian construction manuals such as the "Vastu Sastra" and the "Silpa Sastra" laid out rules for the siting of villages, towns and forts based on the prevailing wind directions and solar orientation. Building layout, street layout and massing were prescribed so as to enhance street level shading, air pollution dispersal and storm water drainage. Vitruvius in "The ten books of Architecture" also considered city layout in relation to local environmental conditions. In the $18^{\text {th }}$ century, the Europeans documented the need of "climate sensitive design" that is crucial for human health and well being in the region. This is evident in the $19^{\text {th }}$ century colonial buildings built with climatic contexts. The interest in city induced climate changes grew out of a concern for human health and comfort conditions. For the sake of street-level thermal comfort Palladio recommended that in cold places the street should be "ample and broad" and in hot places they should be "narrow with high buildings". With the development of Meteorological instruments in the mid-nineteenth century, the scientific investigations of "urban microclimate modifications" increased. Luke Howard (1833) carried out the first scientific study of urban climate modifications. He compared the temperature of a city weather station with that of a rural station and found that the city station was warmer. He found that the night was $3.70^{\circ} \mathrm{F}$ warmer and the day $0.34^{\circ} \mathrm{F}$ cooler in the city than in the country. He attributed this difference to the extensive use of fuel in the city. The warmth of cities in contrast to their rural surroundings is termed as "Urban Heat Island" (UHI), a term coined by Gordon Manley in 1958 (Landsberg 1981). "The heat island is a reflection of the totality of microclimatic changes brought about by man-made alterations of the urban surface" - (Landsberg, 1981). Emilien Renou 1868, in his study in Paris suggests clearly the temperature difference between the countryside and the city is about $1^{\circ} \mathrm{C}$ at the same elevation (Landsberg, 1981). A heat island is a dome of stagnant air over the heavily built-up areas of cities (Akbari et al, 1992). The intensity of heat islands depends on density, population, size - Irving Hoch (Terry A. Ferrar, 1976, Oke, 1982) and morphology (physical structure) of the cities. The rate of cooling in the city depends on two measures of the urban structure that are negatively related: (Oke, 1981), Height - width ratio (H/W, street geometry) - the ratio of the typical height of the buildings to the typical width of the neighbouring streets and the sky view factorthe fraction of the sky hemisphere visible from a location at street level in an infinitely long urban street canyon. The heat island patterns are significantly determined by the unique characteristics of the city. The difference between the maximum urban temperature and the background rural temperature is defined as the urban heat island intensity. UHI have many negative impacts in the built environment. Higher temperatures in cities increases the energy use for cooling, increases health risks and aggravates accumulation of smog due to the existence of high temperatures along with atmospheric pollutants (Santamouris 2002).

Therefore it is vital for urban designers and urban planners to study the nature of the climate variation trends in urban areas to equip them in planning sustainable and comfortable cities thereby reducing the adverse effects. This paper aims at "assessing the intensity of urban heat island effect and defining the relationship between the UHI effect and the urban factors in the city of Chennai".

\section{AREA OF STUDY}

Chennai-Madras, a metropolitan city of India, is located on the Coromandel Coast of the Bay of Bengal. It was founded by the British East India Company in 1639 with Fort St. George as the base. The eastern boundary of the city is the 12-kilometre long Marina Beach. As of 2001 census, Chennai city had a population of 4.2 million, while the total metropolitan population was 6.7 million. The estimated metropolitan population in 2007 was 7.50 million and is the 31 st largest metropolitan area in the world. ("World Gazetteer: India - Metropolitan areas 2008 calculation"). The population density in the city is 24,418 per $\mathrm{km}^{2}$ while the overall population density of the metropolitan area is 5,847 per $\mathrm{km}^{2}$. Chennai located at $13.04^{\circ} \mathrm{N}$ latitude and $80.17^{\circ} \mathrm{E}$ longitude, has a flat coastal plain with an average elevation of $6 \mathrm{~m}$. Two rivers the Cooum in the central region and the Adyar River in the southern region meander through Chennai. The Buckingham Canal which is $4 \mathrm{~km}$ inland travels parallel to the coast, linking the two rivers. The Otteri Nullah, an eastwest stream runs through north Chennai and meets the Buckingham Canal at Basin Bridge.

Chennai experiences hot humid climate due to its proximity to the sea and has little seasonal variation as it lies on the thermal equator. April May and June are the hottest months with maximum temperatures around $38^{\circ} \mathrm{C}$, but it exceeds $40^{\circ} \mathrm{C}$ for a few days in the month of May. The minimum temperatures around $24{ }^{\circ} \mathrm{C}$ are experienced during December and January.

\section{Urban Heat Island in Chennai:}

It is necessary to understand the intensity of $\mathrm{UHI}$ as it would enable us in defining the relationship between the urban factors and the UHI effect. UHI studies in Srilanka (Emmanuel, 1997, 1999, 2000, Johansson, 2006) suggested the thermal comfort patterns are strongly 
correlated to hard land cover changes. Similar study in Singapore (Nichol, 1996, Wong 2006) identified that tropical cities do not have single UHI, but have a collection of small UHIs separated by cooler areas.

In Chennai the first UHI study was conducted by Jayanthi in 1987 (Jayanthi, 1988). The study revealed the existence of UHI in Chennai with three hot pockets namely Mambalam, Vepery and Ennore Industrial zone.

The survey also identified the cool pockets at Guindy RajBhavan area due to considerable amount of vegetation and vast open spaces. The maximum intensity of heat island intensity observed was $4^{\circ} \mathrm{C}$.

Chennai city has foreseen lot of developments in the past twenty years and no study was conducted since 1987. Therefore to understand the nature of urban heat island effect in the present scenario, a study was conducted to assess the intensity of $\mathrm{UHI}$ through mobile and stationary survey during May 2008 (the hottest month) in Chennai city.

To define the relationship between the urban factors and the $\mathrm{UHI}$ intensity it is essential to study the various land uses of Chennai. The major green areas in Chennai include the Guindy National Park, RajBhavan, IIT Madras, Forest reserve near Sembakkam in the southern part of Chennai.

Northern Chennai is primarily an industrial area and the central Chennai is the commercial heart of the city with the downtown area. Southern and Western Chennai, which were predominantly residential areas are currently turning into commercial areas, hosting a large number of IT and financial companies.

\section{METHODOLOGY}

The assessment of the UHI intensity in Chennai was explored through mobile and stationary measurements observed during the hottest month of May 2008.

Air Temperature data were collected using HOBO dataloggers kept inside a white open plastic box which in turn is covered by an outer covering (a vent pipe of $115 \mathrm{~mm}$ dia painted white). Fig. 1 shows a typical instrument setup used for the measurements.

To map a citywide temperature distribution at night when maximum heat island intensity occurs, a mobile survey was conducted. The mobile measurements were collected simultaneously in two fixed return routes covering majority of the locations in the city on $18^{\text {th }}$ May 2008 between 00.20 am to $5.30 \mathrm{am}$, which was accidentally the hottest day of the year.

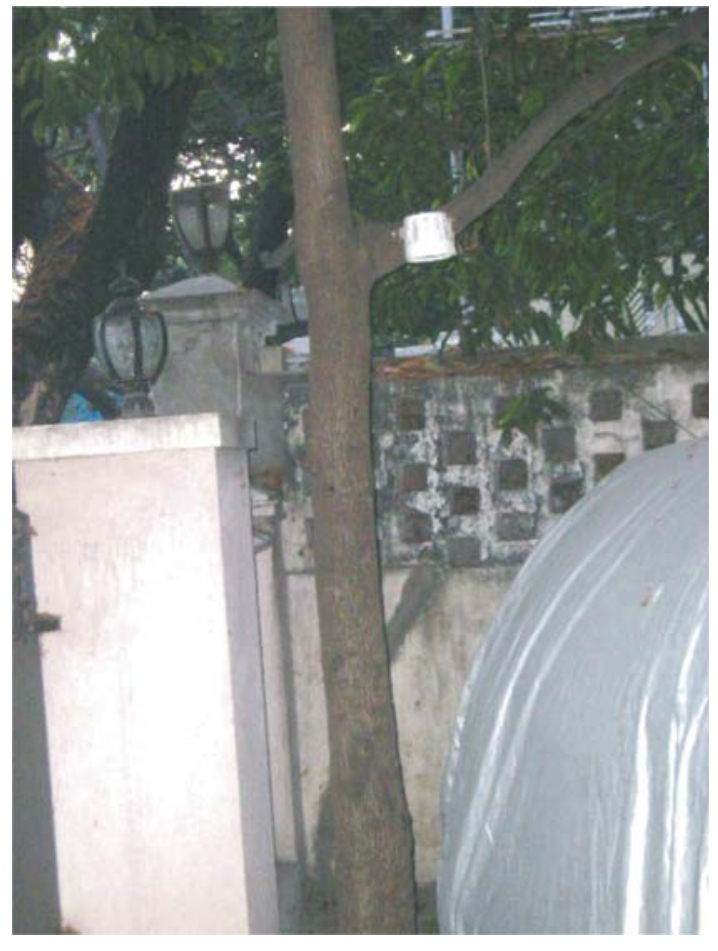

Fig. 1. Typical instrument set up for measurements.

The Instrument was fixed in a PVC pipe tied horizontally to the car at a height of $1.4 \mathrm{~m}$ and approximately $75 \mathrm{~cm}$ in front of the engine. Air temperatures were recorded every 3 minutes along the mobile route. The collected data were averaged for time correction and was used to construct a horizontal thermal map to study the intensity of UHI in Chennai city. An UHI profile for Chennai city is plotted to understand the relationship between the urban factors and the UHI intensity.

Stationary measurements were taken for 30 locations in the city. 16 locations were recorded in the first set from May $4^{\text {th }}$ to $14^{\text {th }}$ and 14 locations in the second set from May $15^{\text {th }}$ to $28^{\text {th }}$. In two locations the data were collected for the entire duration from May $4^{\text {th }}$ to $28^{\text {th }} 2008$. The instruments were fixed either on the utility poles or on tree trunks at a height of $2.5-3 \mathrm{~m}$. The data collected were analyzed to understand the impact of urban built up and other urban parameters on the intensity of $\mathrm{UHI}$.

\section{SITE SELECTION}

The Chennai city region covers an area of $174 \mathrm{~km}^{2}$ and the metropolitan region covers $1,177 \mathrm{~km}^{2}$. The study area of Chennai includes both the city and the metropolitan region. It was divided into concentric circles with fort St. George as the centre, as the city development was in a radial fashion with Fort St. George as the center. Fig. 2 shows the mobile routes, the stationary locations of measurements and the two meteorological stations 
(Nungambakkam and Meenambakkam). Table 1 shows the characteristics of the stationary locations.

The stationary locations for measurements were chosen so that the radiating lines from the center cover the city, suburban and rural locations to equip in plotting the UHI profile of Chennai. The two mobile routes were chosen in such a way it covers most of the locations in the city covering urban, suburban and rural areas. The Nungambakkam meteorological station is located within the city and is characterized with commercial establishments dominated with public buildings and has a high density and very high traffic. The Meenambakkam meteorological station is an airport station located in the suburbs of Chennai. 14 urban stations, 9 suburban stations and 7 rural locations were chosen for the study. The growth pattern of the city is by and large along the three major National Highways namely NH4, NH45 and $\mathrm{NH} 5$. The rural stations are chosen along these major highways.

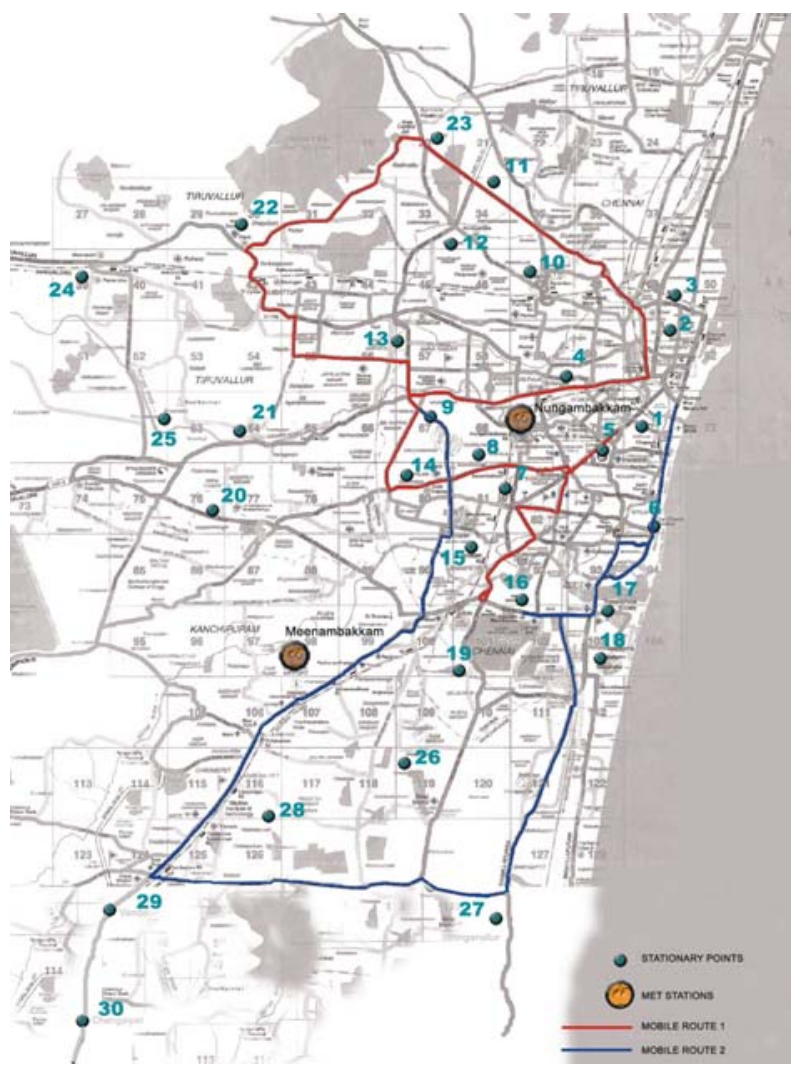

Fig. 2. Mobile routes and Stationary locations.

\section{RESULTS AND DISCUSSION}

The data collected through the mobile survey conducted in two fixed return routes were plotted to show the temperature mapping of Chennai city (Fig. 3). The results indicated the presence of cool islands in Thirumangalam, Valluvarkottam, Anna University, Gemini

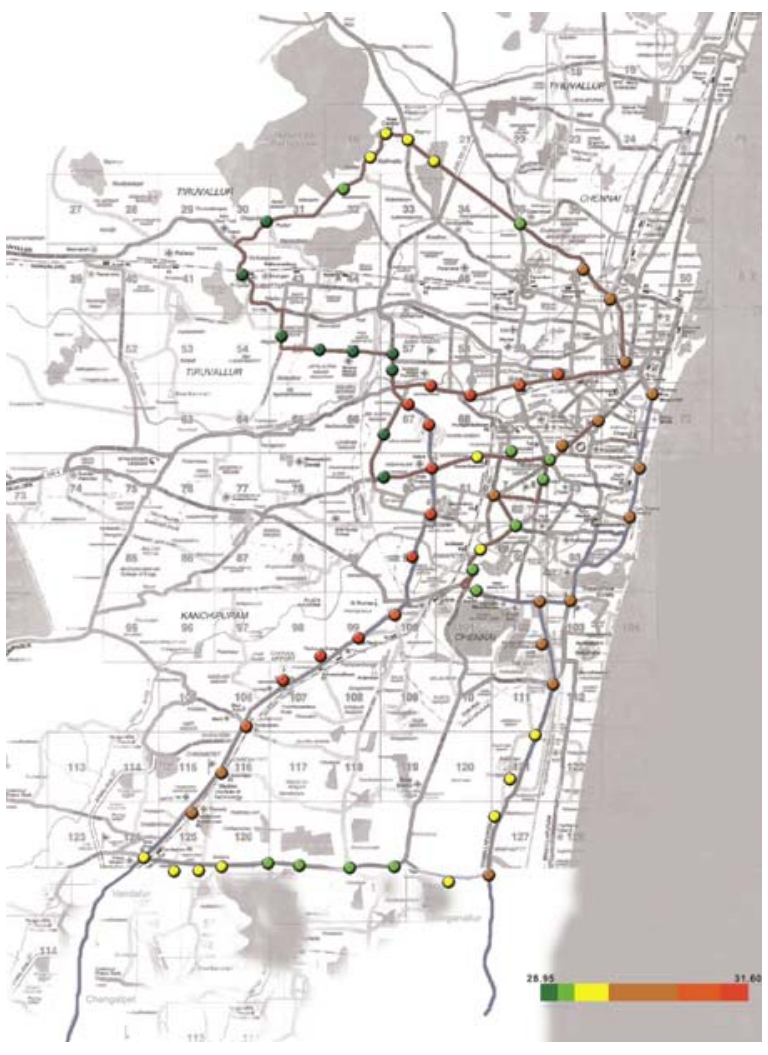

Fig. 3. Temperature distribution mapping based on the mobile survey.

flyover, Shanthi colony and at RajBhavan areas in Chennai. It also helped in identifying the heat pockets at Mount Road, Koyambedu, Kathipara junction (Guindy) and Meenambakkam airport areas. These hot spots are caused by large areas of exposed hard surfaces on site, such as concrete surfaces, runways and bus parking bays. In addition all these hot pockets are characterized by very high traffic leading to increase in anthropogenic heat emissions. The increased anthropogenic heat and the hard surfaces results in higher air temperatures. Lower temperatures recorded within the city near RajBhavan area attributes to the presence of dense vegetation, whereas at Thirumangalam, Gemini flyover, Shanthi colony and Valluvarkottam it is mainly due to the presence of open spaces, parks etc representing cool pockets.

It can be found that lower temperatures were recorded mostly away from the centre (Fort St. George) in a radial fashion. Higher temperatures were observed in the central and northern part with lower temperatures in the southern part. But areas close to the airport region experienced higher temperature due to the 
Table 1. Characteristics of the Stationary Locations.

\begin{tabular}{|c|c|c|c|}
\hline ID No & Location & Classification & Description \\
\hline 1 & Triplicane & Urban & Coastal traditional settlement in the east with high density and high traffic \\
\hline 2 & Parrys & Urban & $\begin{array}{l}\text { A main commercial area in the old city with very high density and very high traffic } \\
\text { with no vegetation }\end{array}$ \\
\hline 3 & Old Washermenpet & Urban & Old settlement with high density, medium traffic and no vegetation \\
\hline 4 & Purasavakkam & Urban & $\begin{array}{l}\text { A perfect mixture of commercial and residential hub with very high density and very } \\
\text { high traffic }\end{array}$ \\
\hline 5 & Mount Road & Urban & Central Business district with high density and very high traffic \\
\hline 6 & Santhome & Urban & $\begin{array}{l}\text { A fishing settlement close to the sea in the east with medium density and medium } \\
\text { traffic }\end{array}$ \\
\hline 7 & T. nagar & Urban & $\begin{array}{l}\text { Primarily a commercial area along with old residential settlements with high } \\
\text { density and very high traffic with few parks. }\end{array}$ \\
\hline 8 & Kodambakkam & Urban & Residential zone with medium density, medium dense vegetation, high traffic \\
\hline 9 & Koyambedu & Urban & $\begin{array}{l}\text { A major hub of activity zone with one of Asia's largest perishable goods market } \\
\text { complex and Asia's largest mofussil bus terminus accompanied by medium } \\
\text { density and very high traffic. }\end{array}$ \\
\hline 10 & Perambur & Suburban & Suburb in North Chennai with medium density and medium traffic \\
\hline 11 & Madavaram & Suburban & An institutional zone with low density and medium traffic \\
\hline 12 & Kolathur & Suburban & Newly developing residential area with low density and low traffic \\
\hline 13 & Thirumangalam & Urban & $\begin{array}{l}\text { Primarily a residential neighbourhood with medium dense vegetation, medium } \\
\text { density and medium traffic }\end{array}$ \\
\hline 14 & Virugambakkam & Suburban & $\begin{array}{l}\text { One of the fastest growing residential neighbourhood with medium density and } \\
\text { medium traffic }\end{array}$ \\
\hline 15 & Saidapet & Urban & Largely a residential area with medium density and medium traffic \\
\hline 16 & Anna University & Urban & $\begin{array}{l}\text { An institutional zone close to Guindy national park and Rajbhavan with high } \\
\text { dense vegetation, low density and medium traffic }\end{array}$ \\
\hline 17 & Adayar & Urban & $\begin{array}{l}\text { A neighbourhood in the south highly influenced by the IT sector converting it into } \\
\text { a commercial hub with medium density and high traffic }\end{array}$ \\
\hline 18 & Besant Nagar & Urban & $\begin{array}{l}\text { Primarily residential neighbourhood adjoining the theosophical society and } \\
\text { Kalakshetra academy with medium vegetation, medium density and medium } \\
\text { traffic }\end{array}$ \\
\hline 19 & Nelacherry & Suburban & $\begin{array}{l}\text { A fast developing residential area in south west Chennai with medium density and } \\
\text { medium traffic. }\end{array}$ \\
\hline 20 & Ayyapanthangal & Suburban & Low density residential area with medium traffic and more open areas \\
\hline 21 & Adayalampattu & Rural & A rural low density institutional zone with more open spaces \\
\hline 22 & Ambattur & Suburban & $\begin{array}{l}\text { A residential neighbourhood with low density, low traffic, and medium dense } \\
\text { vegetation }\end{array}$ \\
\hline 23 & Puzhal & Rural & A rural low density area with low traffic close to Puzhal lake \\
\hline 24 & Avadi & Rural & A rural agricultural area with low density and low traffic \\
\hline 25 & Thiruverkadu & Rural & Low density, less traffic with more open spaces and medium vegetation \\
\hline 26 & Kilkattalai & Suburban & A newly developing residential neighbourhood with low density and medium traffic \\
\hline 27 & Sholinganallur & Rural & $\begin{array}{l}\text { A rural institutional zone with low density, medium traffic and more open space } \\
\text { with less vegetation }\end{array}$ \\
\hline 28 & Chrompet & Suburban & $\begin{array}{l}\text { A fast growing residential neighbourhood with medium density, medium traffic and } \\
\text { dense vegetation }\end{array}$ \\
\hline 29 & Vandalur & Rural & $\begin{array}{l}\text { A rural area adjoining Anna Zoological park with dense vegetation, low density } \\
\text { and medium traffic }\end{array}$ \\
\hline 30 & Chengalpet & Rural & A rural low density residential zone with less traffic \\
\hline
\end{tabular}


development of heavy construction activity and traffic congestion in the recent years. The maximum temperature of $31.58^{\circ} \mathrm{C}$ was recorded at Koyambedu and the minimum temperature of $29.05^{\circ} \mathrm{C}$ was recorded at Shanthi colony. Therefore there existed an intensity of $2.53^{\circ} \mathrm{C}$ of heat island in the city of Chennai. Based on the mobile survey, a UHI profile for Chennai was plotted (Fig. 4). The profile clearly indicates the relationship of different land uses, presence of vegetation and the intensity of UHI. In the CBD area, absence of vegetation and high density resulted in elevated air temperatures. In the airport area due to heavy construction activity and increased anthropogenic emission caused the highest temperatures in the UHI profile. The lowest temperatures are owing to the presence of dense forest vegetation at RajBhavan area.

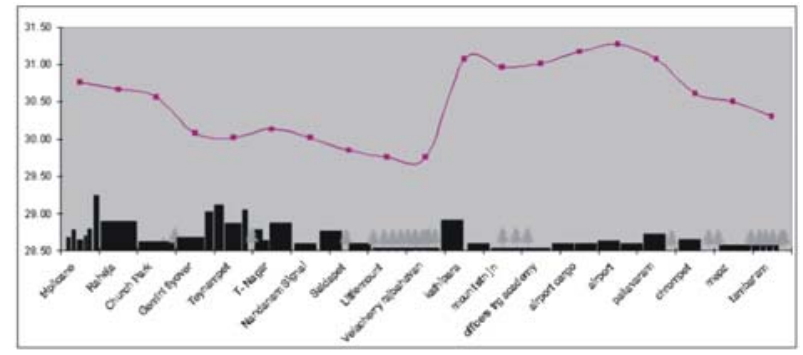

Fig. 4. Sketch of Urban Heat Island Profile in Chennai city.

The Stationary survey also confirmed the heat pockets at all urban locations, except at Anna University. At $4^{\prime} 0 \mathrm{am}$ the maximum urban temperatures of $33.64^{\circ} \mathrm{C}$ was recorded at Mount Road and the minimum urban temperatures of $28.09^{\circ} \mathrm{C}$ was recorded at Anna University. $5.55^{\circ} \mathrm{C}$ intensity of heat island existed within the urban locations. Fig. 5 shows the microclimatic variations amongst various stationary locations.

The maximum daytime temperature recorded by rural, suburban and urban stations are $43.95^{\circ} \mathrm{C}, 42.66^{\circ} \mathrm{C}$, and $41.20^{\circ} \mathrm{C}$ at Avadi, Thirumangalam and Purasawalkam. When compared to urban stations, rural stations experience higher temperatures. This is mainly due to the internal shading of buildings in the urban locations. Similarly the minimum temperatures recorded by rural, suburban and urban stations are $27.54^{\circ} \mathrm{C}$, $27.98^{\circ} \mathrm{C}$, and $27.66^{\circ} \mathrm{C}$ at Avadi, Perambur and Anna University. The lowest temperatures are recorded at the rural locations which indicate the influence of urban factors on increased air temperatures in the city. The minimum temperatures of all urban locations exceptAnna University were higher than $29.04^{\circ} \mathrm{C}$. The increase in minimum temperatures in urban locations is due to the reduced sky view factors in the city resulting in multiple reflection of the absorbed radiation within the streets.

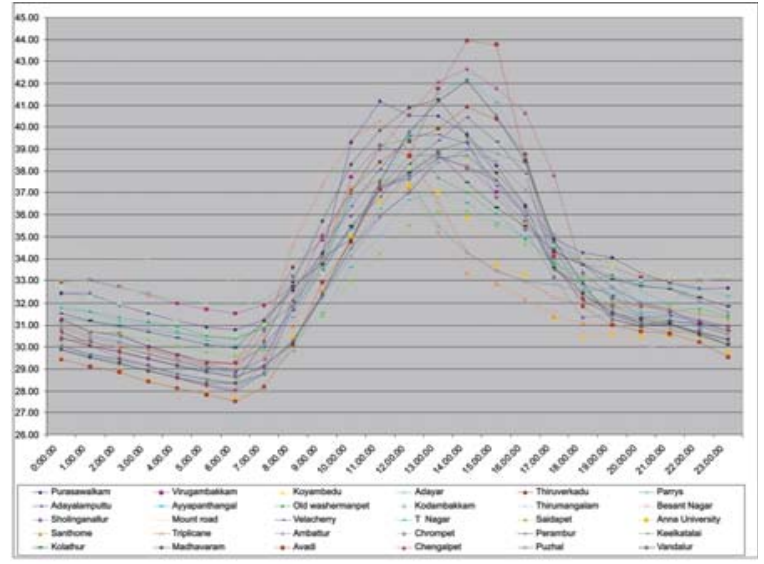

Fig. 5. Microclimatic Variations Amongst Various Stationary Locations

Therefore the urban factors reduce the daytime temperatures and increase the night time temperatures thereby reducing the diurnal variation. These reducing diurnal variations are a clear indication of the existence of heat island effect. The maximum diurnal variations of $16.41^{\circ} \mathrm{C}$ was recorded atAvadi, a rural station and the minimum of $5.25^{\circ} \mathrm{C}$, $6 . .57^{\circ} \mathrm{C}, 6.95^{\circ} \mathrm{C}$ were recorded at Mount Road, Saidapet and T-Nagar, urban stations respectively. Table 2 indicates clearly the nature of $\mathrm{UHI}$ in terms of diminishing diurnal variations on urban, suburban and rural sites. All urban locations indicate the presence of UHI, except Anna University, Santhome and Triplicane. Owing to the close proximity to the shore Santhome and Triplicane escaped from the UHI effect. Sholinganallur, a rural staion experienced lesser diurnal variations when compared to other rural stations. This is due to the development of IT buildings on this stretch. Thriuverkadu and Adayalampattualso experienced lesser diurnal variations

Table 2. Diurnal Variations at various stationary locations

\begin{tabular}{|l|c|c|}
\hline Locations & Classification & $\begin{array}{l}\text { Diurnal } \\
\text { variations } \\
\text { in }{ }^{\circ} \text { C }\end{array}$ \\
\hline Mount road & Urban & 5.25 \\
\hline Saidapet & Urban & 6.57 \\
\hline T Nagar & Urban & 6.95 \\
\hline Parrys & Urban & 7.25 \\
\hline Virugambakkam & Urban & 7.63 \\
\hline Koyambedu & Urban & 7.98 \\
\hline Adayar & Urban & 7.98 \\
\hline Besant Nagar & Urban & 8.34 \\
\hline Kodambakkam & Urban & 8.83 \\
\hline Kolathur & Urban & 8.84 \\
\hline $\begin{array}{l}\text { Old } \\
\text { washermanpet }\end{array}$ & Urban & 9.05 \\
\hline Purasawalkam & Urban & 9.40 \\
\hline
\end{tabular}




\begin{tabular}{|l|c|c|}
\hline $\begin{array}{l}\text { Old } \\
\text { washermanpet }\end{array}$ & Urban & 9.05 \\
\hline Purasawalkam & Urban & 9.40 \\
\hline Anna University & Urban & 9.72 \\
\hline Ambattur & Suburban & 10.01 \\
\hline Santhome & Urban & 10.20 \\
\hline Puzhal & Suburban & 10.34 \\
\hline Sholinganallur & rural & 10.52 \\
\hline Chrompet & Suburban & 10.64 \\
\hline Perambur & Suburban & 10.64 \\
\hline Velacherry & Suburban & 10.76 \\
\hline Keelkatalai & Suburban & 11.05 \\
\hline Adayalamputtu & rural & 11.24 \\
\hline Triplicane & urban & 11.59 \\
\hline Thiruverkadu & rural & 11.68 \\
\hline Thirumangalam & Suburban & 12.74 \\
\hline Madhavaram & Suburban & 12.92 \\
\hline Ayyapanthangal & Rural & 13.28 \\
\hline Vandalur & Rural & 13.46 \\
\hline Chengalpet & Rural & 14.58 \\
\hline Avadi & Rural & 16.41 \\
\hline
\end{tabular}

owing to the increase in anthropogenic heat emission of lorry traffic. Thus, the urban factors results in lesser diurnal variation in the city, which increases the intensity of UHI. The mobile survey and the stationary survey confirm the occurrence of the $\mathrm{UHI}$ effect in the city of Chennai.

\section{CONCLUSION AND RECOMMENDATIONS}

The study confirms the existence of UHI effect in the city of Chennai through mobile and stationary measurements. It indicates an intensity of $5.55^{\circ} \mathrm{C}$ in case of stationary measurements and $2.53^{\circ} \mathrm{C}$ in case of mobile measurements. Vegetation to a large extent can improve the thermal environment. At city level, large green patches can reduce night time air temperatures. At micro level, trees and plants surrounding the built up spaces can reduce the absorption of solar radiation. The $\mathrm{UHI}$ effect is a common feature found in most cities. Therefore the basic strategies applicable to all cities in mitigating the negative impacts of $\mathrm{UHI}$ are shading the hard surfaces that are directly exposed to sun, greening the city and reducing the anthropogenic heat and use of light color materials to save cooling energy.

\section{ACKNOWLEDGEMENT}

The Author is thankful to Ar. Ebin Horrison, Ar. Anitha, Ar. Swetha, and Ms. Subbulakshmi for their help in collecting and compiling the field data.

\section{REFERENCES}

[1] Akbari, $H_{\text {., }}$ and $H$. Taha, 1992: The impact of trees and white surfaces on residential heating and cooling energy use in four Canadian cities. Energy, 17, 141-149.

[2] Baruch Givoni, 1998, Climate Considerations in Building and Urban Design, New York, Van Nostrand Reinhold.

[3] Chandler. T.J., 1976, Urban climatology and its relevance to urban design, WMO Technical note no.149, Geneva.

[4] Clarke. J. F., 1972, Some effects of the urban structure on heat mortality, Environmental Research 5: 93-104.

[5] Emmanuel .R., 1997, Summertime heat island effects of urban design parameters, Ph.D Thesis, University of Michigan, Ann Arbor.

[6] Emmanuel .R., 1999, Trends in urban climate changes in Srilanka: Analysis of urban heat island in major cities, Research sponsored by University of Moratuwa.

[7] Emmanuel. R, 2000, Summertime Urban Heat Island Mitigation: Propositions based on ann investigation of Intra-Urban air temperature variations, Architectural Science Review, 40 (4): 155-164.

[8] Emmanuel. R, 2005. An Urban approach to Climate-Sensitive Design, Strategies for the tropics, London and New York, Spon Press.

[9] Emmanuel, R., Johansson, E., 2006, Influence of urban morphology and sea breeze on hot humid microclimate, the case of Colombo, Sri Lanka,. Climate Research, ms no. C 617.

[10] Erik Johansson, 2006, Urban Design and Outdoor Thermal Comfort in Warm Climates, PhD Thesis, Lund University, Sweden.

[11] Helmut E. Landsberg, 1981, The Urban Climate. New York:Academic Press.

[12] Jayanthi.N, 1988, Heat island study over Madras city and neighbourhood, Research Report, Regional Meteorological Centre, Madras.

[13] Luke Howard, 1833, The climate of London.

[14] Lutz Katzschner, 2002, Behaviour of people in open spaces in dependency of thermal comfort conditions. 
[15] Nichol, J. E., 1996, Analysis of the urban thermal environment with LANDSAT data, Environment and Planning, 23, 733-747.

[16] Oke, T.R. 1976, The distinction between canopy and boundary layer heat islands, Atmosphere, 14 (4), 268-277.

[17] Oke, T.R. 1981, Canyon geometry and the nocturnal urban heat island: Comparison of scale model and field observations. International Journal of Climatology 1, 237-254.

[18] Oke, T.R. 1982, The energetic basis of the urban heat island. Quarterly Journal of the Royal Meteorological Society 108, 1-24.

[19] Oke T.R., 1987, Boundary Layer Climates, London, Methuen.

[20] Santamouris, M, 2002, Energy and Climate in the Urban built Environment. London, James and James Publishers.

[21] Terry A. Ferrar, 1976, The Urban Costs of Climate Modification, John Wiley \& Sons.
[22] Thomas R. Detwyler and Melvin G. Marcus, 1972, Urbanization and Environment, Duxbury Press, Belmont, California.

[23] William P. Lowry, 1988, Atmospheric ecology for designers and planners, McMinnville, Oregon, Peavine Publications

[24] Wong Nyuk- Hien and Chen Yu, 2006, The urban heat island effect in Singapore, Tropical Sustainable Architecture, pp 181-199.

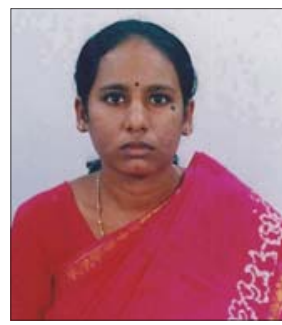

Ms. A. Lilly Rose is a Research Scholar at The School of Architecture and Planning, Anna University, Chennai and an Assistant Professor at the Department of Architecture, Sathyabama University, Chennai. Her field of research is "Urban Heat Island and Built Environment". A post-graduate from The School of Architecture and Planning, Anna University, Chennai, her areas of interest are Climatic Design, Project Management and Building Science. 